\title{
Dehydration Simulation of Natural Gas by using Tri Ethylene Glycol in Kerendan gas field
}

\author{
Eric Farda ${ }^{1}$ \\ ${ }^{1}$ Akademi Migas Balongan
}

\begin{abstract}
Water content in natural gas poses threat to process facilities such as column distillation. Natural gas from reservoirs usually contains water vapor, the presence of water vapor in gas processing causes bad impact to process facilities. Dry Gas composition data was taken from Salamander Energy which is located in the Bangkanai Block and Karendan gas field of Indonesia. Optimization of natural gas dehydration using Tri Ethylene Glycol was carried out using Aspen HYSYS V8.6 with Peng-Robinson fluid package. The natural gas dehydrating plant was designed with operating conditions of 394 bar and $46^{\circ} \mathrm{C}$ and 20 MMSCFD gas flow rate were inputted. Results obtained from HYSYS simulation shows. Three different TEG flowrates were used for this simulation. Results obtained from simulation that. For the purpose of running the plant economically, the minimum flow rate of TEG which will reduce the water content to within the limit of pipeline specification, is very important and the result obtained showed that a minimum of $3 \mathrm{~m} / \mathrm{h}$ of TEG is required to reduce the water content of a gas stream of 20 MMSCFD to 13.6lb/MMSCFD, which is within the limit of $6-7 \mathrm{lb} / \mathrm{MMSCFD}$, this value when compare to gas plant which uses $15 \mathrm{~m}^{3} / \mathrm{h}$ for the gas stream of 20 MMSCFD to achieve the same water content specification is far lower. Values below this flow rate $\left(3.5 \mathrm{~m}^{3} / \mathrm{h}\right) \mathrm{may}$ not reduce the water content to the specified limit.
\end{abstract}

Keywords: Dehydration, Tri Ethylene Glycol, Natural Gas, Absorber, Stripper, Reboiler, Heat Exchanger

Corresponding Author: eric.che.01@gmail.com

\section{INTRODUCTION}

Natural gas is one of the most important fuels in our life and one of the principle sources of energy for many of our day-to-day needs and activities. It is an important factor for the development of countries that have strong economy because it is a source of energy for household, industrial and commercial use, as well as to generate electricity. Natural gas, in itself, might be considered a very uninteresting gas - it is colorless, shapeless, and odorless in its pure form, but it is one of the cleanest, safest, and most useful of all energy sources. Natural gas is the gas obtained from natural underground reservoirs either as free gas or gas associated with crude oil. It generally contains large amounts of methane along with decreasing amounts of other hydrocarbons. Natural gas is considered 'dry' when it is almost pure methane, having had most of the other commonly associated hydrocarbons removed. However, natural gas found at the wellhead, although still composed primarily of methane, is by no means a pure gas. dioxide, helium, nitrogen, and other compounds. The properties of natural gas include gas-specific gravity, pseudocritical pressure and temperature, viscosity, compressibility factor, gas density, and gas compressibility. Knowledge of these property values is essential for designing and analyzing natural gas production and processing systems. In order to meet the requirements for a clean, dry, wholly gaseous fuel suitable for transmission through pipelines and distribution for burning by end users, the gas must go through several stages of processing, including the removal of entrained liquids from the gas, followed by drying to reduce water content. In order to remove water content, dehydration process is used to treat the natural gas. The types of dehydration process used are absorption, adsorption, gas permeation and refrigeration. Absorption is the transfer of a component from the gas phase to the liquid phase, and is more favorable at a lower temperature and higher pressure. Water vapor is removed from the gas by intimate contact with a hygroscopic liquid desiccant in absorption dehydration. The contact is usually achieved in packed or trayed towers. Glycols have been widely used as effective liquid desiccants. Dehydration by absorption with glycol is usually 
economically more attractive than dehydration by solid desiccant, though both processes are capable of meeting the required dew point.

Salamander Energy (Bangkanai) Limited (SEBL) plan to develop a gas processing facility in Kerendan gas field, wich is located in at Bangkanai PSC Block. This Block is located in some $200 \mathrm{~km}$ west of Balikpapan and $330 \mathrm{~km}$ north of Banjarmasin, the provincial capitals of East and West Kalimantan respectively. The Block is situated on the west side of Kutai Basin and the northern edge of the stable Barito shelf. Kerendan gas field comprises four wellhead, called as K-04, K-06, K-07 and K-08 with provision 3 additional wellheads for future development. The production from the four wellheads will be collected at manifold in the well head cluster pad, and then sent to Kerendan Gas Processing Facilities (KGPF) via gathering pipeline. Production will be predominantly gas, with the maximum of 25 MMScfd and associated condensate and produced water of $300 \mathrm{bpd}$ and $1870 \mathrm{bpd}$ respectively. The Kerendan Production will be processed in the KGPF, which should meet the product specification for sales to the third party. The sales gas wil be distributed to PT PLN (Persero) via sales gas pipeline, while the condensate wil be stored in the condensate stored tank and will be exported via road tanker. PT PLN (Persero) requests require about 20 mmscfd.

\section{METHODOLOGY}

The design and simulation of the natural gas dehydration plant, using HYSYS was utilized in this work to achieve the desired objectives. A case study package of the software was used in the analysis; such that different quantity and flow rate of TEG was imposed on the plant to determine the various quantity of water removed.

The commonly available glycols and their uses are described as follows (Katz et al., 1959).

1. Monoethylene glycol (MEG); high vapor equilibrium with gas so tend to lose to gas phase in contactor. Used as hydrate inhibitor where it can be recovered from gas by separation at temperatures below $50^{\circ} \mathrm{F}$.

2. Diethylene glycol (DEG); high vapor pressure leads to high losses in contactor. Low decomposition temperature requires low reconcentrator temperature $\left(315\right.$ to $\left.340^{\circ} \mathrm{F}\right)$ and thus cannot get pure enough for most applications.

3. Triethylene glycol (TEG); most common. Reconcentrate at $340-400^{\circ} \mathrm{F}$, for high purity. At contactor temperatures in excess of $120^{\circ} \mathrm{F}$, there is a tendency to high vapor losses. Dewpoint deppressions up to $150^{\circ} \mathrm{F}$ are possible with stripping gas.

4. Tetraethylene glycol (TREG); more expensive than TEG but less loss at high gas contact temperature . Reconcentrate at $400-430^{\circ} \mathrm{F}$.

TEG is far the most common liquid desiccant used in natural gas dehydration.

\section{PROCESS DESCRIPTION}

As shown in figure of Hysys simulation, wet natural gas first typically enters an inlet separator to remove all liquid hydrocarbons from the inlet gas stream. Gas then flows to absorber where it is contacted countercurrently and water is absorbed by TEG. Dry natural gas then exiting the absorber passes through a 
gas/TEG heat exchanger and then into the splitter and then flow to separator in order to separate water before flow to sales line. The rich TEG exiting the absorber flows through a coil in the accumulator where it is preheated by hot lean TEG. After the TEG-TEG heat exchanger, the rich TEG enters the stripping column and flows down the packed bed section into the reboiler. The hot regenerated lean TEG flows out of the reboiler where it is cooled via cross exchange with returning rich TEG; it is pumped to a TEG/gas heat exchanger and back to the top of absorber

\section{Absorber}

The incoming wet gas and the lean TEG are contacted countercurrently in the absorber to reduce the water content of the gas to the required specifications. The key design parameters for the absorber are : gas flow rate and specific gravity, gas temperature, operating pressure, outlet dew point or water content required. The water removal rate, assuming the inlet gas is water saturated, can be determined as :

$$
W_{r}=\frac{Q_{G}\left(W_{i}-W_{o}\right)}{24}
$$

$\mathrm{W}_{\mathrm{r}}=$ water removed, $\mathrm{lb} / \mathrm{hr}$

$\mathrm{W}_{\mathrm{i}}=$ water content of inlet gas, lb/MMscf

$\mathrm{W}_{\mathrm{o}}=$ water content of outlet gas, $\mathrm{lb} / \mathrm{MMscf}$

$\mathrm{QG}=$ gas flow rate, $\mathrm{MMscfd}$

The make up of TEG is determined on the basis of the amount of water content of water to be removed and is usually between 2 and 6 gallons of TEG per pound of water removed. Higher circulation rates provide little additional dehydration while increasing reboiler fuel and pumping requirements. An excessive circulation rate may overload the reboiler and prevent good TEG regeneration. An increase in circulation rate may decrease reboiler temperature, decreasing lean TEG concentration, and actually decrease the amount of water that is removed by the TEG from the gas.

The minimum TEG circulation rate can then be calculated as :

$$
Q_{T E G, \min }=G x W_{r}
$$

$$
\begin{array}{ll}
\text { QTEG,min } & =\text { minimum TEG circulation rate }(\text { gal TEG/hr }) \\
\mathrm{G} & =\text { TEG-to-water ratio }(\text { gal TEG/lb water removed }) \\
\mathrm{W}_{\mathrm{r}} & \text { = water removed, } \mathrm{lb} / \mathrm{hr}
\end{array}
$$

The diameter of the absorber and the number of absorber stages are selected on the basis of the gas and glycol flow rates and gas-specific gravity. The diameter of the contactor (absorber) can be estimated from the Souders and Brown (1932) correlation.

$$
V_{\max }=K_{S B}\left[\frac{\rho_{L}-\rho_{G}}{\rho_{G}}\right]=\left[\frac{4 Q_{G}}{\pi D^{2}}\right]
$$

$$
\begin{array}{ll}
\mathrm{D} & =\text { internal diameter glycol contactor }(\mathrm{m}) \\
\mathrm{QG}_{\mathrm{G}} & =\text { gas volumetric flowrate }\left(\mathrm{ft}^{3} / \mathrm{hr}\right) \\
\mathrm{V}_{\max } & =\text { maximum superficial gas velocity }(\mathrm{ft} / \mathrm{hr}) \\
\mathrm{KsB} & =\text { Souders and Brown coefficient }(\mathrm{ft} / \mathrm{hr}) \\
\rho_{\mathrm{L}} & =\text { glycol density, } \mathrm{lb} / \mathrm{ft}^{3} \\
\rho_{\mathrm{G}} & =\text { gas density at column condition }\left(\mathrm{lb} / \mathrm{ft}^{3}\right)
\end{array}
$$

Some operators prefer bubble cap trays because they are suitable for viscous liquids, handle high turndown ratios and low liquid/gas ratios well, and are not subject to weeping. Calculated tray efficiency values are 
dependent on the TEG/water equilibrium data used. To achieve an accurate design method, column efficiencies consistent with accurate equilibrium data must be therefore recommended.

\section{Stripper}

The still or stripper column is used in conjunction with the reboiler to regenerate the glycol. On many dehydrators, the still is placed vertically on top of the reboiler so that vapor from the reboiler directly enters the bottom of the distillation column. A given lean TEG concentration is produced in the reboiler and still column (regenerator) section by the control of reboiler temperature, pressure, and the possible use of a stripping gas.

\section{Reboiler}

The reboiler supplies heat to regenerate the rich glycol in the still by simple distillation. The separation is relatively easy because of the wide difference in boiling points of water and glycol. Reboiler duty can be estimated by the following equation:

$$
\mathrm{QR}=900+966(\mathrm{G})
$$

$\mathrm{QR} \quad=$ regenerator duty $\left(\mathrm{Btu} / \mathrm{lb} \mathrm{H}_{2} \mathrm{O}\right.$ removed $)$

$\mathrm{G} \quad=$ glycol- to water ratio (gal TEG/lb $\mathrm{H}_{2} \mathrm{O}$ removed)

The reboiler normally operates at a temperature of 350 to $400 \circ \mathrm{F}$ for a TEG system; this temperature controls the lean glycol water concentration. The purity of the lean glycol can be increased by raising the reboiler temperature, but TEG starts to decompose at $404 \circ \mathrm{F}$. The reboiler should not be operated above $400^{\circ} \mathrm{F}$ to allow a safety margin to prevent decomposition, and the burner should have a high temperature shutdown for safety. The heat flux in the reboiler must be high enough for vaporization, but not so high as to cause glycol decomposition.

\section{Heat Exchanger}

Two types of heat exchangers are found in glycol plants: glycol/glycol and gas/glycol.

\section{Glycol/Glycol Exchanger}

A glycol/glycol exchanger cools the lean glycol while preheating the rich glycol. For small standard designs, the integral exchanger is economical to fabricate but may not heat the rich glycol above $200 \circ \mathrm{F}$.

\section{Dry Gas/Lean Glycol Exchanger}

This type of exchanger uses the exiting dry natural gas to control the lean glycol temperature to the splitter. Temperatures that are too low promote glycol loss due to foaming and increase the glycol's hydrocarbon uptake and potential still vent emissions

\section{Glycol Circulation Pump}

A circulation pump is used to move the glycol through the unit. The gas/glycol pump is common in field TEG dehydrators where electricity is typically not available. A reciprocating pump is sized using manufacturer's catalogs or by the standard mechanical energy balance and an assumed pump efficiency of $70-80 \%$.

$$
\begin{gathered}
\text { Pump BHP }(\text { Brake Horse Power })=2 \times 10^{-7}(\mathrm{QTEG})(\mathrm{P}) \\
\text { Electrical kW }=1.833 \times 10^{-7}(\mathrm{QTEG})(\mathrm{P})
\end{gathered}
$$

QTEG = TEG circulation rate

$\mathrm{P} \quad=$ system pressure $(\mathrm{psig})$

\section{Splitter}

The splitter column is used to separate TEG liquid and sales Gas. 


\section{Separator}

The separator column is used separate Sales Gas and remaining water.

Tabel 1 Feed Gas Composition and Process Conditions (Salamander Energy (Bangkanai) Limited)

\begin{tabular}{cc}
\hline Components & $\begin{array}{c}\text { Composition } \\
(\boldsymbol{\%} \text { mole })\end{array}$ \\
\hline $\mathbf{H}_{\mathbf{2}} \mathbf{S}$ & 0 \\
\hline $\mathbf{C O}_{\mathbf{2}}$ & 2.88 \\
\hline $\mathbf{N}_{\mathbf{2}}$ & 1.55 \\
\hline $\mathbf{C}_{\mathbf{1}}$ & 87.83 \\
\hline $\mathbf{C}_{\mathbf{2}}$ & 3.65 \\
\hline $\mathbf{C}_{\mathbf{3}}$ & 1.34 \\
\hline $\mathbf{i}-\mathbf{C}_{\mathbf{4}}$ & 0.41 \\
\hline $\mathbf{n}-\mathbf{C}_{\mathbf{4}}$ & 0.47 \\
\hline $\mathbf{i}-\mathbf{C}_{\mathbf{5}}$ & 0.24 \\
\hline $\mathbf{n}-\mathbf{C}_{\mathbf{5}}$ & 0.22 \\
\hline $\mathbf{n}-\mathbf{C}_{\mathbf{6}}$ & 0.23 \\
\hline $\mathbf{C}_{\mathbf{7}}-\mathbf{C}_{\mathbf{9}}$ & 0.61 \\
\hline $\mathbf{C}_{\mathbf{1 0}}-\mathbf{C}_{\mathbf{1 2}}$ & 0.29 \\
\hline $\mathbf{C}_{\mathbf{1 3}}-\mathbf{C}_{\mathbf{1 4}}$ & 0.13 \\
\hline $\mathbf{C}_{\mathbf{1 5}+}$ & 0.16 \\
\hline $\mathbf{H}_{\mathbf{2}} \mathbf{O}$ & saturated \\
\hline Total $_{\mathbf{1}}$ & 100 \\
\hline & \\
\hline
\end{tabular}

Tabel 2 Inlet Gas Operating Condition (Salamander Energy (Bangkanai) Limited)

\begin{tabular}{cc}
\hline Temperature & $46^{\circ} \mathrm{C}$ \\
\hline Pressure & 394 bar \\
\hline Flow Rate & 20 MMSCFD / 6.8 MMSCFD
\end{tabular}

The composition of the natural gas stream is saturated with water, prior to entering the Contactor. This is to demonstrate the effectiveness of the TEG in the contactor. The gas compositions and conditions are inputted into the HYSYS software and simulated. 


\section{SIMULATION}

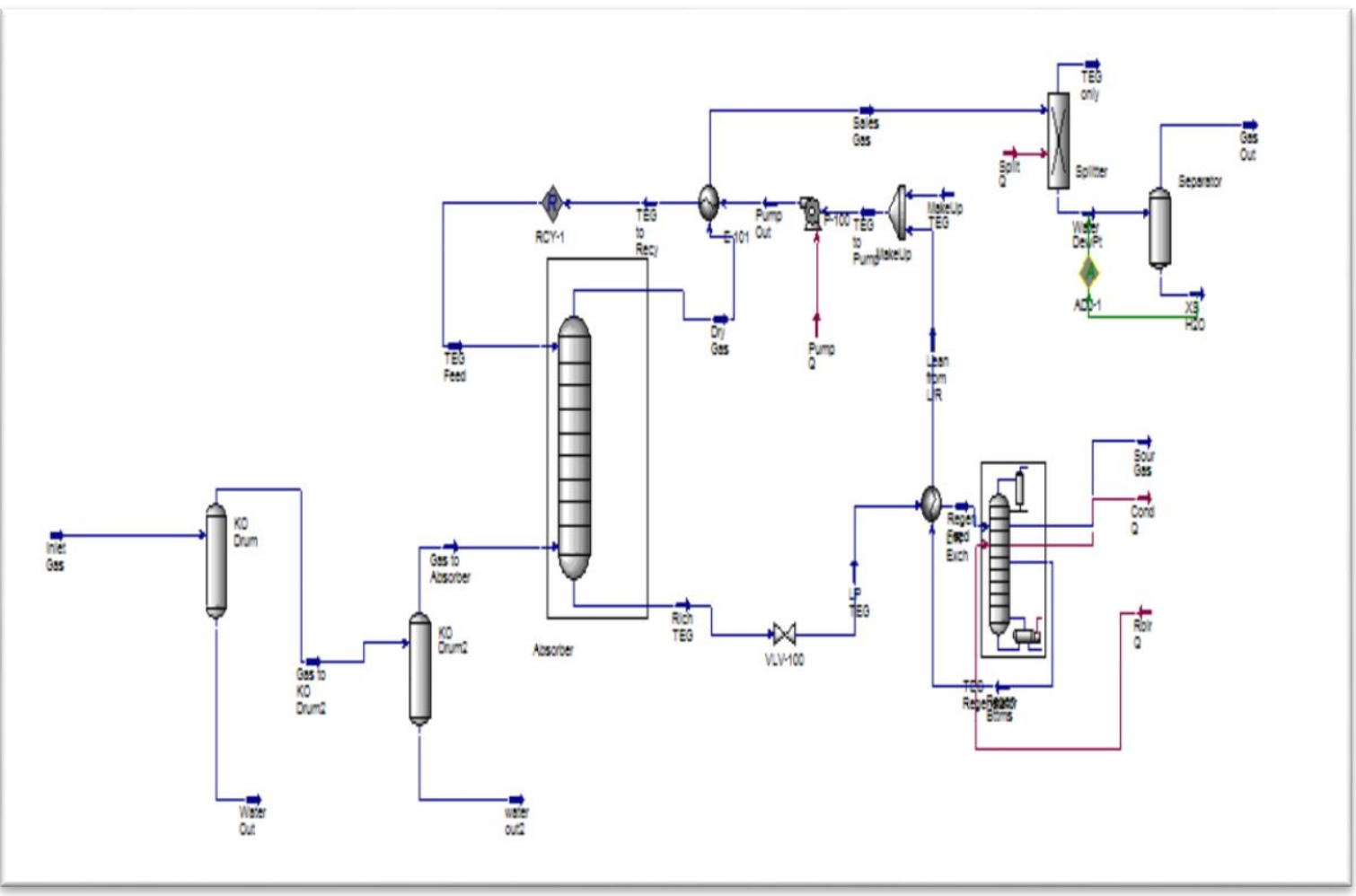

Figure 1. Hysys Simulation

The inlet gas will accommodate four wellhead, called as K-04, K-06, K-07 and K-08 with provision 3 additional wellheads for future development in 2018. This simulation considers gas production, associated condensate and water produced with using TEG to dry the gas untul 2036.

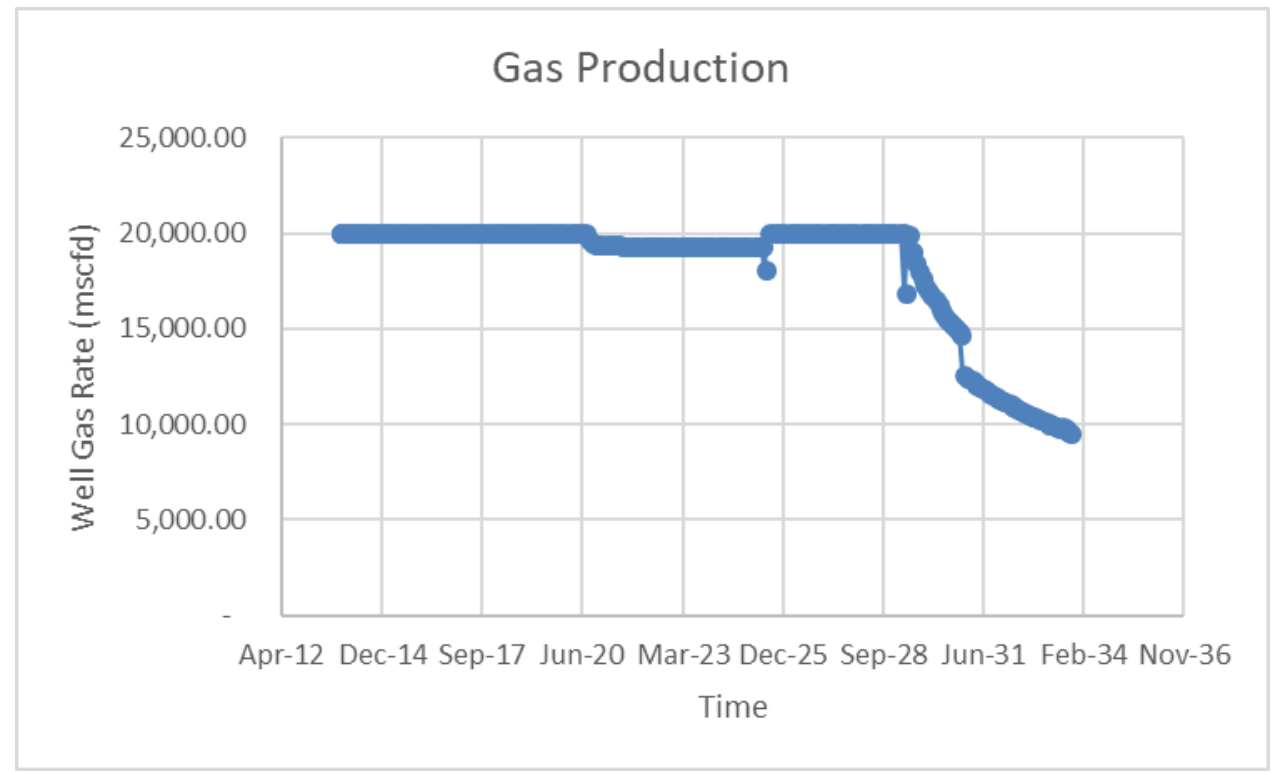

Figure 2. Gas Production 


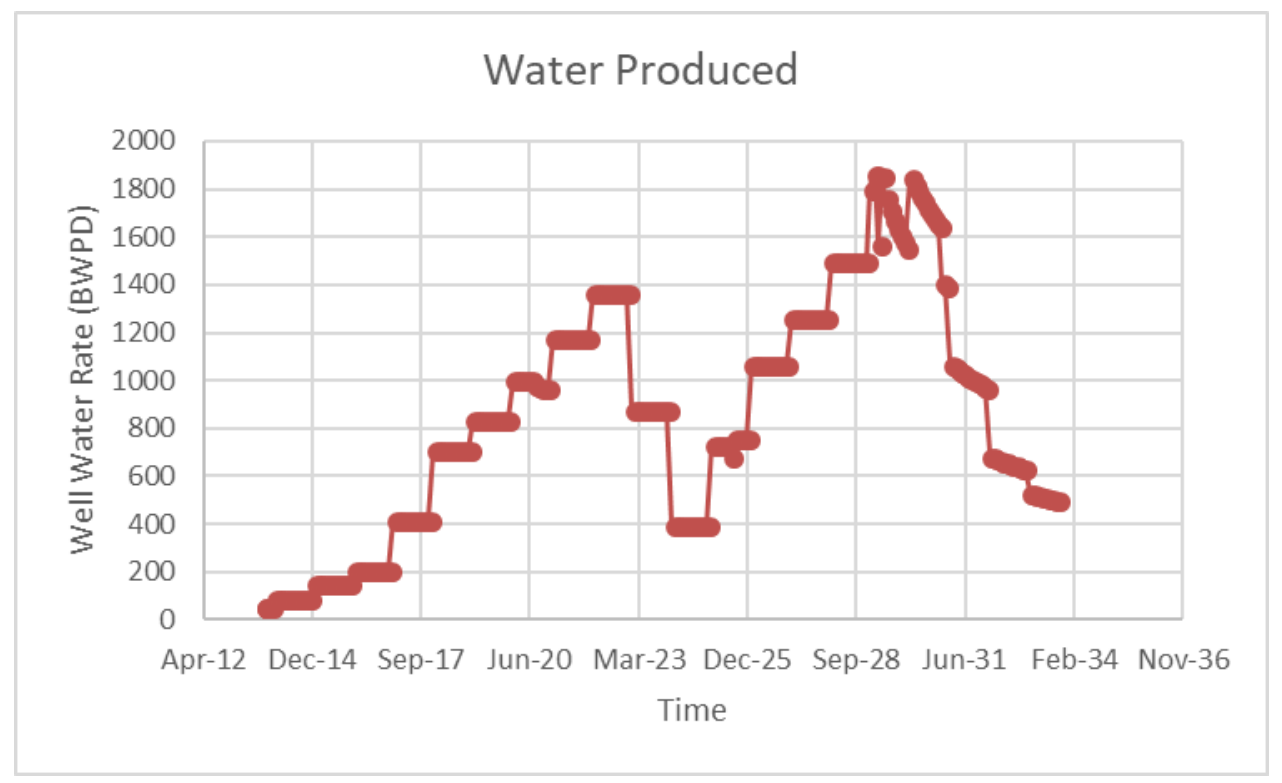

Figure 3. Water Produced

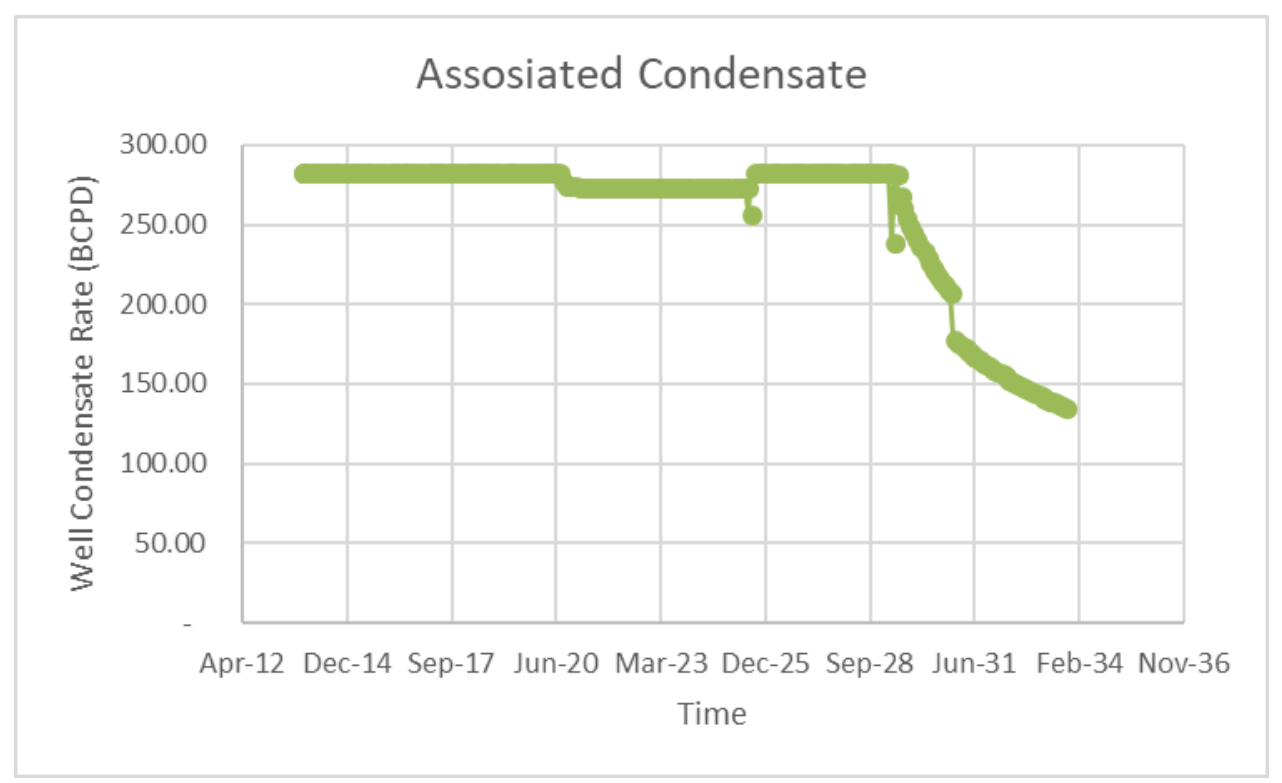

Figure 4. Assosiated Condensate

\section{RESULTS AND DISCUSSION}

Natural gas is usually saturated with water from the reservoir, removing this water is a major task for the process engineers. Natural gas facilities are designed to handle water removal from the gas stream to meet pipeline specification of water content in the processed gas stream. With the use of HYSYS software, natural 
gas dehydration plant was designed; process conditions and compositions were inputted and simulated. Results obtained show that water content in natural gas stream from reservoirs can be reduced to the pipeline specification limit. However, different water contents in the processed gas stream were obtained for different flow rates of TEG. For the purpose of running the plant economically, the minimum flow rate of TEG which will reduce the water content to within the limit of pipeline specification, is very important and the result obtained showed that a minimum of $3 \mathrm{~m}^{3} / \mathrm{h}$ of TEG is required to reduce the water content of a gas stream of $20 \mathrm{MMSCFD}$ to $13.6 \mathrm{lb} / \mathrm{MMSCFD}$, which is within the limit of 6-7 lb/MMSCFD, this value when compare to gas plant which uses $15 \mathrm{~m}^{3} / \mathrm{h}$ for the gas stream of $20 \mathrm{MMSCFD}$ to achieve the same water content specification is far lower. Values below this flow rate $\left(3.5 \mathrm{~m}^{3} / \mathrm{h}\right)$ may not reduce the water content to the specified limit. This will pose threat to process facilities because of hydrate formation and cannot be tolerated when transporting the gas to a region of low temperature. From the result, the company can run gas plant more economically with a TEG flow rate of $3.5 \mathrm{~m}^{3} / \mathrm{h}$ or slightly above that.

\section{CONCLUTION}

1. With this Hysys simulation, it can be seen that the gas distributing PT PLN (Persero) fulfilled, namely 20 MMSCFD fulfilled until the month of May 2029.

2. by using TEG on Kerendan gas field, is very helpful in dehydration gas with water that maximum production that is $1867 \mathrm{BWPD}$.

\section{REFERENCES}

(Salamander Energy (Bangkanai) Limited) Ltd (2011), Kerendan Gas Project - Basic of Design. 5st Edition API STD 521 (2007), Pressure Relieving and Depressuring

API RP 14E (1997), Recommended Practice for Design and Installation of Offshore Production Platform Piping Systems

Arthur Kohl, Richard Nielsen (1997): Gas Purification (5th ed.), Gulf Publishing Company, Houston, Texas, chapter 11.

Chi U. Ikoku (1992): Natural Gas Production Engineering The Pennsylvania State University, Krieger Publishing Company, Malabar, Florida, chapter 4 Separation and Processing.

Dan Laudal Christensen (2009): “Thermodynamics Simulation of Water/Glycol Mixture" Aalborg University Esbjerg.

M. Stewart, and K. Arnold (2011). Gas Sweetening and Processing Field Manual. Houston: Gulf Professional Publishing, pp. 51-52.

R.V. Smith: Practical Natural Gas Engineering (2nd ed.). PennWell Publishing Company, Tulsa, Oklahoma.

Saeid Mokhatab, William A. Poe, James G. Speight (2011): Handbook of Natural Gas and Processing. Gulf Professional Publishing, page. 323-341. 